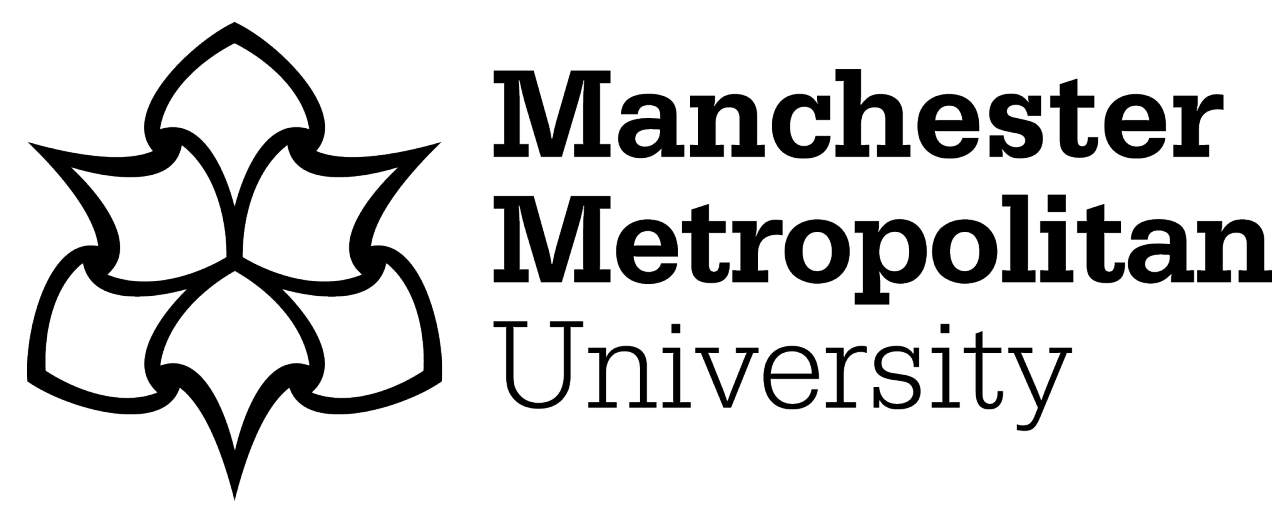

Latham, Annabel ORCID logoORCID: https://orcid.org/0000-0002-84107950 and Goltz, Sean (2019) A Survey of the General Public's Views on the Ethics of using Al in Education. In: Lecture Notes in Artificial Intelligence 11625 - AIED 2019. Lecture Notes in Computer Science, 11625. Springer Nature, Switzerland. ISBN 978-3-030-23203-0

Downloaded from: https://e-space.mmu.ac.uk/622786/

Version: Accepted Version

Publisher: Springer Nature

DOI: https://doi.org/10.1007/978-3-030-23204-7_17

Please cite the published version 


\title{
A Survey of the General Public's Views on the Ethics of using AI in Education
}

\author{
Annabel Latham ${ }^{1[0000-0002-8410-7950]}$ and Sean Goltz ${ }^{20000-0002-3032-1660]}$ \\ ${ }^{1}$ Manchester Metropolitan University, Manchester M1 5GD, UK \\ ${ }^{2}$ Business \& Law School, Edith Cowan University, Perth, Australia \\ a. lathamemmu.ac.uk \\ n.goltz@gmail.com
}

\begin{abstract}
Recent scandals arising from the use of algorithms for user profiling to further political and marketing gain have popularized the debate over the ethical and legal implications of using such 'artificial intelligence' in social media. The need for a legal framework to protect the general public's data is not new, yet it is not clear whether recent changes in data protection law in Europe, with the introduction of the GDPR, have highlighted the importance of privacy and led to a healthy concern from the general public over online user tracking and use of data. Like search engines, social media and online shopping platforms, intelligent tutoring systems aim to personalize learning and thus also rely on algorithms that automatically profile individual learner traits. A number of studies have been published on user perceptions of trust in robots and computer agents. Unsurprisingly, studies of AI in education have focused on efficacy, so the extent of learner awareness, and acceptance, of tracking and profiling algorithms remains unexplored. This paper discusses the ethical and legal considerations for, and presents a case study examining the general public's views of, AI in education. A survey was recently taken of attendees at a national science festival event highlighting state-of-the-art AI technologies in education. Whilst most participants $(77 \%)$ were worried about the use of their data, in learning systems fewer than $8 \%$ of adults were 'not happy' being tracked, as opposed to nearly two-thirds $(63 \%)$ of children surveyed.
\end{abstract}

Keywords: Ethics, Trust, GDPR.

\section{Introduction}

Although discussions of the ethics of Artificial Intelligence (AI) have been commonly found in popular writing and science fiction for decades, it is only relatively recently that the field of AI has become sufficiently advanced to bring the issues of an ethical and legal framework to the fore. The mainstream use of apps and search engines has led to the collection of large amounts of user interaction data, from which an increasing number of attributes can be inferred about the individual. Whilst for companies this has led to more efficient, highly targeted advertising campaigns, the question of whether this offers a benefit to the user, in terms of filtering information, or holds the 
risk of unwitting persuasion, hangs in the balance. Since 2011 Eli Pariser has campaigned to raise awareness of the dangers of algorithmic personalization by search engines such as Google, warning that "the Internet is showing us what it thinks we want to see, but not necessarily what we need to see" [1]. Shoshana Zuboff argues that knowledge and power are now asymmetrical in the business of 'surveillance capitalism', a major part of which is personalized communication, and that people's belief that they get something in return for their data is misled [2]. A major study of youth behavior online concluded that an important reason why most youths appear unconcerned about profiling by digital technology was a "lack of knowledge" rather than a "cavalier attitude toward privacy" [3]. Recent scandals involving the use of algorithms for user profiling to further political and marketing gain (e.g. Cambridge Analytica's alleged use of personal information to profile individual US voters for targeted political advertising [4]) have resulted in much publicity about the dangers of big data and algorithmic decision making in everyday lives. However, whether this additional publicity has translated into public awareness is still a subject for debate.

In education, research into the application of AI techniques to learning systems for the benefit of the learner has been an active field for several decades. The benefits of personalized, adaptive learning have long been argued and supported by results that show that learners can learn more efficiently and effectively with the inclusion of AI techniques as opposed to without $[5,6]$. However, it is open to debate how many members of the general public have actually had access to learning systems that use AI techniques, or even if they have, whether they are aware of the use of AI profiling. With the popular use of apps that adapt to make our lives more convenient, AI techniques have moved into the mainstream and user expectations have shifted accordingly, so that many people would not categorize features such as predictive text or recommendation systems as using $\mathrm{AI}$ at all.

In order to benefit from the personalization of learning using AI techniques, learners must accept the trade-off of the system gathering personal data and tracking their learning experience. In fact, just like the Facebook / Cambridge Analytica scandal, learning systems use an individual's behavior within a system to infer information about personality, mood, learning styles and comprehension [7-11]. The question arises "How many learners are aware and understand that in order to personalize, learning systems gather user data in order to profile their personal traits?".

Whilst there have been a few studies investigating the public's perception of AI in everyday lives [12-13], none have yet been published that specifically explore the issue of AI in education - and whether the perceived benefit of the educational context has any impact on views of AI generally. This pilot study aims to fill this gap by gathering views of AI in the Educational context. Its results will be of interest to AIED researchers, educators, and researchers with an interest in the legal and ethical aspects of AI.

This paper describes a survey of the general public's feelings on the use of AI in education. The survey involved collecting anonymous questionnaires completed voluntarily by some attendees at a free National Science Festival event held at Manchester Science Museum, called 'Me versus Machine'. The event included a number of activities designed to introduce people of different ages to Computer Science. One 
stand was dedicated to Artificial Intelligence in Education, where recent research in Conversational Intelligent Tutoring Systems was demonstrated and discussed. Interested attendees were asked to participate in a study of views on AI in Education, and completed a questionnaire.

The rest of the paper is organized as follows: Section 2 considers the legal and ethical context of AI and its use in education. Section 3 outlines profiling in education systems, with section 4 presenting a case study of the general public's views on AI in education, followed by the conclusion in section 5 .

\section{Legal and Ethical Considerations of AI in Education}

\subsection{Ethical Issues of $\mathrm{AI}$ in Education}

The discussion of ethics in AIED is not new. In 2000, Aiken and Epstein published an article in the International Journal of Artificial Intelligence in Education titled 'Ethical Guidelines for AI in Education: Starting a Conversation' [14]. While the cited predictions for the future of AIED for 2010 are somewhat premature, most will agree that this is what we are expecting today, 20 years later, for 2025: "The teacher of 2010 will rarely spend a day lecturing... The artificial-intelligence tutor will become a valuable assistant, providing the individualized instruction that a teacher with 20 or more pupils does not have the time for. Learning can take place at the student's pace." [15].

Following Shneiderman's [16] quote from Louis Mumford [17]: "The real question before us lies here: do these instruments further life and enhance its value, or not?", Aiken and Epstein propose two fundamental meta-principles as a basic philosophical underpinning for any discussion of AIED systems: 1) "The Negative Meta-Principle for AIED - AIED technology should not diminish the student along any of the fundamental dimensions of human being; and 2) The Positive Meta-Principle for AIED AIED technology should augment the student along at least one of the fundamental dimensions of human being" [14].

Fast forward 20 years, and Nichols and Holmes propose eight principles constituting "an open ethical framework for implementing AI in educational setting in ways that empower students and provide transparency" [18]. These principles are required since while data is supposed to be applied in objective ways by AI, source data is not immune from bias and there is no such thing as "raw data" [19].

It is already established that algorithms designed by engineers to process data carry in them inherent bias with ethical consequences as was illustrated by sexist, racist and discriminatory consequences by AI systems [20]. The recent Cambridge Analytica scandal [21] further illustrates that even small amounts of personal data can be combined through AI algorithms with the potential to undermine democracy. The ethical issues faced by data analytics are shared with AI since they both draw on data [22].

While there is a consensus that ethical principles of AI are mandatory and urgent [23], and while multiple organizations are exploring this realm [21, 24-27], there is over representation to AI developers (e.g., DeepMind Ethics and Society) and the corporate perspective (e.g., OpenAI) raising questions whether they will be thinking broadly and critically enough [28]. 
With advances in AIED like the Ada [29] and Jill Watson [30] bots, the absence of a definite reference point for AI ethics is crucial to AIED ethics. Holmes argues that "around the world, virtually no research has been undertaken, no guidelines have been provided, no policies have been developed, and no regulations have been enacted to address the specific ethical issues raised by AIED” [31].

\subsection{The Impact of GDPR}

The General Data Protection Regulation (GDPR) was approved by the EU parliament on April 14, 2016 and came into force on May 25, 2018 (EUGDPR.org). According to the EUGDPR website, "The aim of the GDPR is to protect all EU citizens from privacy and data breaches in today's data-driven world" [32].

Certain aspects of the GDPR are particularly relevant to Artificial Intelligence. One of these is the principle of "accountability," which is an implicit requirement under the current law but has been explicitly introduced in the GDPR [33]. This principle requires organizations to demonstrate compliance with all the other principles in the GDPR, and several further provisions of the GDPR also promote accountability.

Another aspect relevant to $\mathrm{AI}$ is the tightened requirements for consent in the GDPR. The use of AI techniques by its nature (i.e., the collection and processing of massive amounts of data) stipulates that it would be challenging to obtain explicit consent from the individuals involved. This is especially relevant to AIED as the users are often minors, thus requiring both their own and their parents' explicit consent.

A further relevant challenge is the GDPR right to receive an explanation by a natural person of decisions based on automated processing. This right's scope and eligibility is not without doubts [34]. Nonetheless, even if we assume the right for explanation exists, AI decisions are made by complex and technical processes many times not even clear to their developers (e.g., neural networks). In addition, the algorithm structure and operation method may be proprietary information and considered a trade secret. Finally, it would be challenging to explain complex AI systems to a layperson, moreover to a minor.

To manage these challenges raised by AI and the GDPR regulations, the Ministers of the European Parliament (MEPs) asked the European Commission in February 2017, to propose EU-wide rules on robotics and AI. Following this request, a public consultation was held in October 2017. Interestingly, the consultation results showed that European public opinion appears to be much more positive towards automation technologies than U.S. public opinion, based on the results of a recently-release report by the Pew Research Centre [35].

Furthermore, in December 2018, the European Commission's High-Level Expert Group on Artificial Intelligence (AI HLEG) published its draft of the AI Ethics Guidelines for comments from the public with the aim to have a final version in March 2019 [36]. The group have adopted EU treaties and legislation on human rights as their ethical principles for AI. This has led to the following assertion: "It should also be noted that, in particular situations, tensions may arise between the principles when considered from the point of view of an individual compared with the point of 
view of society, and vice versa. There is no set way to deal with such trade-offs.". In the context of AIED, the potential for such tension is high.

While the global (and mainly the Western) discussion around general ethical guidelines for AI is vibrant, there is yet to be a consensus around an established set of principles that would be easily applied to the different fields in which AI is applied. Moreover, as in many cases of challenging regulatory spheres in the past, the surplus of sources and mix of laws (e.g., privacy), regulation (e.g., GDPR), codes (The Asilomar AI Principles [37]) and standards (e.g., IEEE [38]) that apply to AI seems to complicate the problem and make compliance ever more challenging, rather than promoting its solution.

\section{$3 \quad$ Profiling in Learning Systems}

\subsection{Intelligent Tutoring System Approaches}

Intelligent Tutoring Systems (ITS) personalize learning based on traits of the individual learner held in a student model. Traditionally, student models were based on outcomes from ITS-designed assessment and self-reported affective information such as mood, motivation and learning style [39, 40]. More recently, construction of student models has been automated with ITS profiling learner behaviors, such as user interface interactions, to predict the affective state of a learner [8-11]. Most automated profiling techniques map tracked learner behaviors to typical behaviors described in psychological models (e.g. personality and learning styles [10]) to infer learner traits and preferences. Some ITS profile learner affect using physical indicators gathered from sensors worn by learners [41-42].

Conversational Intelligent Tutoring Systems (CITS) are ITS with a conversational agent interface, enabling them to conduct tutoring via a mixed initiative conversation. Their advantage is that the learner does not have to self-motivate as the CITS leads the tutoring conversation, yet learners can ask questions and explore answers using natural language conversation. CITS capture rich interaction information from the conversation, that adds depth to the student model $[6,10,11]$.

\subsection{Oscar CITS}

Oscar CITS aims to mimic a human tutor by delivering a personalized tutoring conversation based on an individual learner's knowledge and preferred learning style $[10,43]$. Oscar CITS incorporates intelligent techniques to provide realtime problem solving support (hints), intelligent solution analysis (feedback) and curriculum sequencing. Learners are automatically profiled using 41 variables tracked based on behavior, preferences and language during the tutorial conversation [43]. Oscar CITS adapts to learner knowledge and learning style, by changing the style of conversation and support material presented, such as giving step-by-step help, giving examples or showing movies $[10,44]$. Oscar CITS is used in a live learning/teaching environment 
at Manchester Metropolitan University to help higher education students learn the database language SQL. ${ }^{1}$

\subsection{Hendrix CITS}

Hendrix CITS is a new generation of CITS that can profile a learner in near-realtime using images from a webcam [11]. Hendrix CITS automatically profiles learners by analyzing images from a webcam to determine whether or not the learner is demonstrating comprehension. This enables Hendrix to intervene in the tutoring conversation if it detects that the learner may need help, thus helping to maintain learner motivation and improve learning. Hendrix CITS tracks a learner's micro expressions, and uses a classification model built from an array of neural networks to determine whether there is a state of non-comprehension, and if so, the level of noncomprehension. Unlike other image-based approaches to profiling affective states, Hendrix does not require lab conditions or high specification cameras to capture sufficient information to profile learner comprehension. ${ }^{1}$

\section{Case Study - Manchester Science Festival}

\subsection{Overview}

The Manchester Science Festival is one of the largest in the UK. The week-long series of events attracts over 130,000 visitors each year. On Saturday 20 October 2018, the 'Platform for Investigation: Me versus Machine' event enabled the public to explore Artificial Intelligence through eight innovative activities designed to engage all ages in computer science and debate its place in our shared future. Organised by computer scientists from Manchester Metropolitan University (MMU), the all-day event took place at Manchester Science and Industry Museum and included hands-on activities, a live experiment, coding challenges and demonstrations of cutting-edge research.

One activity was called 'I, Teacher', an exhibit to introduce families to the use of AI methods in education and learning systems. The exhibit included posters showing which different AI technologies have been included in Intelligent Tutoring Systems to help learners, a conversational agent research timeline and an introduction to automatic learner profiling. A large HDTV continuously ran video demonstrations ${ }^{1}$ of two different Conversational Intelligent Tutoring Systems, Oscar CITS and Hendrix (see section 3), annotated to show the AI techniques being used. The posters and demonstration videos allowed attendees to read and watch by themselves, or to engage in discussion with researchers about the use of AI in education. Questionnaires were placed on a table at the exhibit, and interested members of the public were asked if they would like to record their opinions of AI in education, anonymously and voluntarily.

1 Video demonstrations of Oscar CITS and Hendrix CITS intelligent techniques can be found at www.AnnabelLatham.co.uk. 


\subsection{Methods}

A questionnaire was designed to elicit opinions from the general public on their Internet use, use of their online data, and their views on the use of AI in education. The questionnaire was designed to fit on a single side of A4 and used a Likert scale to facilitate ease and speed of completion (see Table 1). The only demographic information collected was age group and gender, and the questionnaire was completely anonymous. A second version of the questionnaire was developed for children (minors aged 5-18), which included age-appropriate language (scoring a Flesch-Kincaid Grade Level of 5.0 [45]) and three questions with fewer/different choices (Q1, Q5 and Q6 in Table 1). All other questions were the same in content. For participants aged under 18 , the responsible adult's consent was indicated by writing their initials on the child's questionnaire. This indication of consent was accepted under the research ethics approval (MMU EthOS reference number: 1181) as the facilities at the event did not allow for secure storage of personal data recorded on a full consent form.

Participation by members of the public was entirely voluntary. To take part they approached the 'I, Teacher' exhibit, had the process explained and then decided to take part by completing the anonymous questionnaire.

\subsection{Results and Discussion}

During the six hour event, 625 visitors (415 adults, 210 children) passed through the 'Platform for Investigation' exhibition. No data was recorded on how many people visited the 'I, Teacher' exhibit and engaged in discussions with researchers, although the exhibit was very busy all day. It was found through conversation that most people knew the term Artificial Intelligence, but did not necessarily understand its meaning in detail and were mostly not aware that AI had been applied to learning systems. There was much interest in the new research, and in discussing the future possibilities for education, but unsurprisingly most visitors to the stand were reluctant to spend time completing a questionnaire.

38 members of the public decided to complete the questionnaire, however six questionnaires were either largely incomplete or no parental consent had been recorded, so were destroyed. In total there were 32 completed questionnaires, 24 from adults and 8 from minors. There were slightly more male adults (14) than female (9), with one participant not recording gender, and a gender balance of minors. The distribution across age groups is as follows: 5-10 (3); 11-14 (3); 15-18 (2); 19-25 (5); 26-40 (9); 41-60 (10); 61+ (0). Table 1 shows the combined results.

My Data. Interestingly, participants are most comfortable being automatically tracked by online shopping and learning systems (Q2: 62\% and 60\% respectively). This may indicate that the benefit and convenience of such profiling is seen to outweigh any perceived threat. This stands in contrast to search engines like Google and social media where most participants (62\% and 59\% respectively) were not comfortable with tracking, despite the daily use of these applications being high (84\% and $72 \%) .75 \%$ of participants are concerned about the use of their data (Q3) and no participants believe that their Internet use is 'Very' private (Q4). This suggests that safety messages 
Table 1. Combined Questionnaire results. $(n=32 ; n($ children $)=8 ; n($ adults $)=24)$

\begin{tabular}{|c|c|c|c|c|c|}
\hline \multicolumn{6}{|l|}{ My Internet Use } \\
\hline 1. How often do you use & Daily & Weekly & Monthly & Rarely & Never \\
\hline Social media & $72 \%$ & $13 \%$ & $0 \%$ & $0 \%$ & $15 \%$ \\
\hline Google, or similar search engines & $84 \%$ & $3 \%$ & $3 \%$ & $6 \%$ & $4 \%$ \\
\hline YouTube (children) & $86 \%$ & $0 \%$ & $0 \%$ & $14 \%$ & $0 \%$ \\
\hline Online shopping (children) & $29 \%$ & $14 \%$ & $0 \%$ & $0 \%$ & $57 \%$ \\
\hline Online games (children) & $50 \%$ & $17 \%$ & $0 \%$ & $17 \%$ & $16 \%$ \\
\hline Amazon (adults) & $29 \%$ & $33 \%$ & $13 \%$ & $17 \%$ & $8 \%$ \\
\hline Online supermarkets (adults) & $0 \%$ & $32 \%$ & $20 \%$ & $40 \%$ & $8 \%$ \\
\hline \multicolumn{6}{|l|}{ My Data } \\
\hline $\begin{array}{l}\text { 2. How comfortable are you/would you be with } \\
\text { automatic tracking of your use of }\end{array}$ & Very & Quite & $\begin{array}{l}\text { Don't } \\
\text { know }\end{array}$ & Not very & $\begin{array}{c}\text { Not at } \\
\text { all }\end{array}$ \\
\hline Internet generally & $13 \%$ & $22 \%$ & $12 \%$ & $25 \%$ & $28 \%$ \\
\hline Social media & $9 \%$ & $22 \%$ & $10 \%$ & $34 \%$ & $25 \%$ \\
\hline Google, or similar search engines & $19 \%$ & $13 \%$ & $6 \%$ & $31 \%$ & $31 \%$ \\
\hline Online shopping & $34 \%$ & $28 \%$ & $10 \%$ & $6 \%$ & $22 \%$ \\
\hline Learning systems & $44 \%$ & $16 \%$ & $18 \%$ & $0 \%$ & $22 \%$ \\
\hline $\begin{array}{l}\text { 3. How concerned are you about the use of } \\
\text { your data? } \\
\text { 4. How private do you believe your existing }\end{array}$ & $41 \%$ & $34 \%$ & $10 \%$ & $6 \%$ & $9 \%$ \\
\hline Internet use is? & $0 \%$ & $22 \%$ & $15 \%$ & $25 \%$ & $38 \%$ \\
\hline \multicolumn{6}{|l|}{ Artificial Intelligence in Education } \\
\hline 5. How useful do you think AI tools are for & Very & Quite & $\begin{array}{l}\text { Don't } \\
\text { know }\end{array}$ & Not very & $\begin{array}{c}\text { Not at } \\
\text { all }\end{array}$ \\
\hline School learning & $56 \%$ & $38 \%$ & $6 \%$ & $0 \%$ & $0 \%$ \\
\hline Supporting homework/revision & $50 \%$ & $41 \%$ & $3 \%$ & $6 \%$ & $0 \%$ \\
\hline Replacing a face-to-face course & $25 \%$ & $19 \%$ & $12 \%$ & $31 \%$ & $13 \%$ \\
\hline Giving extra learning support & $59 \%$ & $31 \%$ & $7 \%$ & $3 \%$ & $0 \%$ \\
\hline Learning new skills (adults) & $48 \%$ & $44 \%$ & $4 \%$ & $4 \%$ & $0 \%$ \\
\hline Work-based training (adults) & $36 \%$ & $48 \%$ & $4 \%$ & $12 \%$ & $0 \%$ \\
\hline $\begin{array}{l}\text { 6. If an AI learning tool was available, would } \\
\text { you use it for }\end{array}$ & Yes & Maybe & $\begin{array}{l}\text { Don't } \\
\text { know }\end{array}$ & $\begin{array}{l}\text { Probably } \\
\text { not }\end{array}$ & No \\
\hline Your own learning & $66 \%$ & $25 \%$ & $3 \%$ & $6 \%$ & $0 \%$ \\
\hline Replacing textbooks & $31 \%$ & $31 \%$ & $6 \%$ & $19 \%$ & $13 \%$ \\
\hline Helping with homework/revision (children) & $71 \%$ & $15 \%$ & $0 \%$ & $0 \%$ & $14 \%$ \\
\hline Children's/grandchildren's learning (adults) & $64 \%$ & $24 \%$ & $0 \%$ & $8 \%$ & $4 \%$ \\
\hline Replacing face-to-face learning (adults) & $16 \%$ & $24 \%$ & $12 \%$ & $36 \%$ & $12 \%$ \\
\hline Alongside face-to-face learning (adults) & $72 \%$ & $16 \%$ & $4 \%$ & $0 \%$ & $8 \%$ \\
\hline $\begin{array}{l}\text { 7. Do you think AI will help/could have helped } \\
\text { improve your education/learning? }\end{array}$ & $56 \%$ & $38 \%$ & $3 \%$ & $0 \%$ & $3 \%$ \\
\hline \multirow{2}{*}{$\begin{array}{l}\text { 8. How important do you think humans are (vs } \\
\text { computers) in teaching/learning? }\end{array}$} & Very & Quite & $\begin{array}{l}\text { Don't } \\
\text { know }\end{array}$ & Not very & $\begin{array}{c}\text { Not at } \\
\text { all }\end{array}$ \\
\hline & $50 \%$ & $38 \%$ & $3 \%$ & $9 \%$ & $0 \%$ \\
\hline
\end{tabular}


from media and schools have been understood, although it may also be a result of visiting other exhibits at which data privacy issues were discussed.

AI in Education. There was a very positive response to the use of AI in education, with most participants believing such tools to be useful in all scenarios (Q5). Surprisingly, even the controversial question about replacing face-to-face learning (Q5) showed a balance of opinion $-44 \%$ for and $44 \%$ against, with $40 \%$ of adults saying they may use an AI tool instead of face-to-face learning (Q6). In spite of this, $88 \%$ of participants feel that humans are important in teaching and learning. 94\% of participants believe that an AI tool could improve their learning. This suggests that a blended approach to learning is most favorable to the general public, which is consistent with generally accepted practice.

Gender Differences. For adults there were no real differences between genders in the use of the Internet, although there were differences in opinions on tracking and use of data, as shown in Fig. 1. A fifth of males $(21 \%)$ were not concerned about use of their data (Q3), unlike females $(0 \%)$, despite there being no difference in opinion on data privacy (Q4). All males believed AI tools to be useful for work-based learning, versus two thirds $(66 \%)$ of females, and $93 \%$ of males believed humans important in teaching/learning versus $66 \%$ of women.

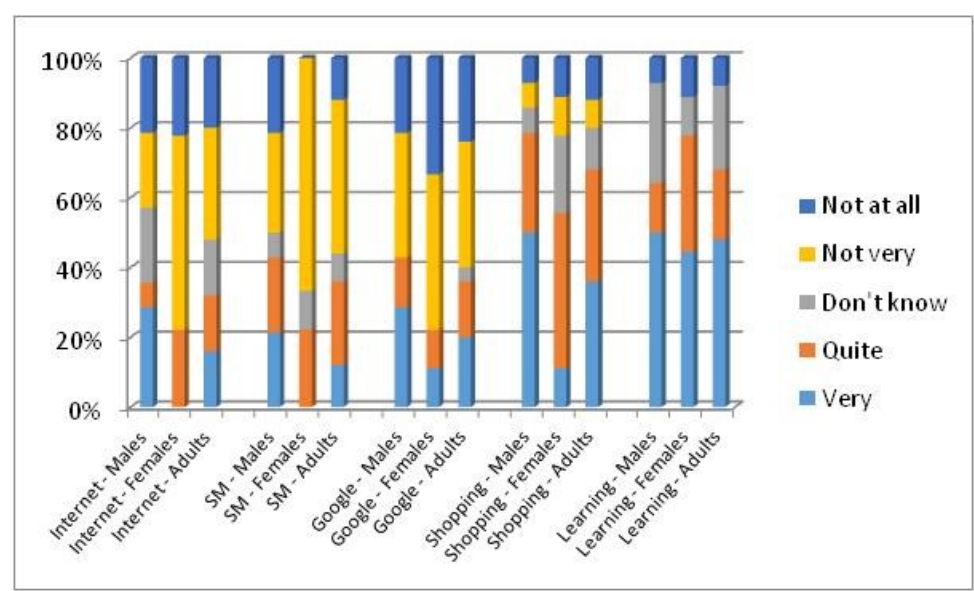

Fig. 1. 'How comfortable are you with automatic tracking': Comparison of Adult's Opinions by Gender.

Age Differences. As expected, minors and adults differ in Internet use. Despite such small numbers it was interesting to see in Q2 that all 5-10 year olds were 'Not at all' happy with being tracked by any of the suggested applications, which stood apart from all other groups. Conversely, the only three participants 'Not at all' worried about use of their data (Q3) were minors. One notable disparity between minors and adults was in automatic tracking by learning systems (Q2) where $63 \%$ of minors (all of 5-10 year olds) were not happy to be tracked, versus only $8 \%$ of adults. 
In summary, the participants in this study were aware of automated tracking and data privacy issues. On the whole, females are less comfortable being automatically tracked than males, suggesting that safety concerns outweigh the convenience offered. In a learning context, more males than females believe that humans are important. However, most participants believed that AI tools were useful in learning, with $94 \%$ believing they could help improve their own learning.

The limitations of the study were that it was a small set of the general public, all of whom were attending an event that highlighted the latest research in AI and its associated legal, social and ethical issues. It would be interesting to see if a larger, more targeted study, taken in a different context, noted different views on profiling and the use of AI in education. A comparison between larger sets of participants in different age groups would also add depth and may highlight important differences in communicating a balanced view of AI tools to the general public.

\section{Conclusion}

This paper has explored the current ethical and legal framework within which AI in Education operates and presented the results of a small study in which the general public shared their views on the use of AI in education systems. It was apparent that participants had not previously been exposed to the idea of using AI algorithms in learning systems, but that in general there was a positive response to the idea, with most participants believing such tools to be useful and stating that if available, they would use them to improve their own learning. Most participants were aware of privacy concerns with their use of the Internet and social media apps, and were not comfortable with their interactions being tracked (despite using such apps daily), although it was interesting to note that more than half of participants were comfortable being tracked by shopping and learning systems. This suggests that the public felt that the benefits outweighed the threats in these contexts. The sample size was small, so future work will involve a larger study in a more general public context to further explore the public's views on trust regarding the use of $\mathrm{AI}$ in education.

The ethical challenges of AI seem to be amplified in an education context due to several characteristics, for example, the dealing with minors, the sensitive nature of the personal information involved and the importance of this application along with its potential benefit to learners. Therefore, it may be beneficial to consider a top-down approach in which the general principles of AI will be informed by the specific ethical principles of AIED and not vice versa.

Ethical approval. All procedures performed in studies involving human participants were in accordance with the ethical standards of the institutional and/or national research committee and with the 1964 Helsinki declaration and its later amendments or comparable ethical standards. Manchester Metropolitan University EthOS ref. 1181.

Acknowledgements. The study described in this paper was supported by Manchester Metropolitan University, IEEE Women in Engineering United Kingdom and Ireland, IEEE Women in Computational Intelligence and Manchester Science Museum. 


\section{References}

1. Pariser, E.: The Filter Bubble: What The Internet Is Hiding From You. Penguin, London (2011).

2. Zuboff, S.: Big Other: Surveillance Capitalism and the Prospects of an Information Civilization. Journal of Information Technology (30), 75-89 (2015).

3. Hoofnagle, C.J., King, J., Li, S., Turow, J.: How different are young adults from older adults when it comes to information privacy attitudes and policies? SSRN Electronic Journal, http://www.ssrn.com/abstract=1589864, last accessed 2019/02/02 (2010).

4. The Cambridge Analytica Files | The Guardian, https://www.theguardian.com/news/series/cambridge-analytica-files, last accessed 2019/02/02.

5. Burns, H., Luckhardt, C. A., Parlett, J. W., Redfield, C. L.: Intelligent Tutoring Systems: Evolutions in Design. Psychology Press, 1991.

6. Van Lehn, K.: The Relative Effectiveness of Human Tutoring, Intelligent Tutoring Systems, and Other Tutoring Systems. Educational Psychologist, 46(4), 197-221 (2011).

7. Fallout from Facebook data scandal may hit health research | New Scientist, https://www.newscientist.com/article/2164521-fallout-from-facebook-data-scandal-mayhit-health-research/, last accessed 2019/02/02.

8. Lin, H. C. K., Wu, C. H., Hsueh, Y. P.: The influence of using affective tutoring system in accounting remedial instruction on learning performance and usability. Computers in $\mathrm{Hu}-$ man Behavior 41, 514-522 (2014).

9. Ammar, M.B., Neji, M., Alimi, A.M., Gouardères, G.: The affective tutoring system. Expert Systems with Applications 37(4), 3013-3023 (2010).

10. Latham, A., Crockett, K., McLean, D., Edmonds, B.: A conversational intelligent tutoring system to automatically predict learning styles. Computers \& Education 59(1), 95-109 (2012).

11. Holmes, M., Latham, A., Crockett, K., O'Shea, J.D.: Near Real-Time Comprehension Classification with Artificial Neural Networks: Decoding e-Learner Non-Verbal Behavior. IEEE Transactions on Learning Technologies 11(1), 5-12 (2018).

12. Hengstler, M., Enkel, E., Duelli, S.: Applied artificial intelligence and trust-The case of autonomous vehicles and medical assistance devices. Technological Forecasting and Social Change 105, 105-120 (2016).

13. König, M., Neumayr, L.: Users' resistance towards radical innovations: The case of the self-driving car. Transportation research part F: traffic psychology and behaviour 44, 4252 (2017).

14. Aiken, R.M., Epstein, R.G.: Ethical guidelines for AI in education: Starting a conversation. International Journal of Artificial Intelligence in Education 11, 163-176 (2000).

15. Hines A.: Jobs and infotech: Work in the information society. The Futurist 28(1), 9-11 (1994).

16. Shneiderman, B.: Human values and the future of technology: a declaration of responsibility. ACM SIGCAS Computers and Society 29(3), 5-9 (1999).

17. Mumford, L.: Technics and Civilization. Harcourt Brace and World, Inc., New York (1934).

18. Nichols, M., Holmes, W. (2018). Don't Do Evil: Implementing Artificial Intelligence In Universities. Towards Personalized Guidance and Support for Learning. In: Proceedings of the 10th European Distance and E-Learning Network Research Workshop, p. 109. Barcelona (2018). 
19. Gitelman L., Jackson V. Introduction. In: Gitelman L. (ed.) "Raw data" is an oxymoron, pp. 1-14. The MIT Press, Cambridge, Massachusetts (2013).

20. Artificial Intelligence's white guy problem. The New York Times, last accessed 2018/08/06. https://www.nytimes.com/2016/06/26/opinion/sunday/artificial-intelligenceswhite-guy-problem.html

21. UK wants to lead the world in tech ethics...but what does that mean? |Ada Lovelace Institute, last accessed 2018/08/10. https://www.adalovelaceinstitute.org/uk-wants-to-lead-theworld-in-tech-ethicsbut-what-does-that-mean/

22. Prinsloo, P., Slade, S.: Student vulnerability, agency and learning analytics: An exploration. Journal of Learning Analytics 3(1), 159-182 (2016).

23. Boddington P. Towards a code of ethics for artificial intelligence. Springer International Publishing, Cham (2017).

24. Trust and transparency, last accessed 2018/08/13. http://lcfi.ac.uk/projects/ai-trust-andsociety/trust-and-transparency/

25. Social well-being and data ethics | Ada Lovelace Institute, last accessed 2018/08/10. https://www.adalovelaceinstitute.org/socialwell-being-and-data-ethics-tim-gardamsspeech-to-techuk-digital-ethics-summit/

26. DeepMind announces ethics group to focus on problems of AI. Technology | The Guardian, last accessed 2018/08/10. https://www.theguardian.com/technology/2017/oct/04/google-deepmind-aiartificialintelligence-ethics-group-problems

27. About OpenAI, last accessed 2018/08/13. https://openai.com/about/

28. Making artificial intelligence socially just: Why the current focus on ethics is not enough | British Politics and Policy at LSE, last accessed 2018/07/06. https://blogs.lse.ac.uk/politicsandpolicy/artificial-intelligence-and-society-ethics/

29. Bolton College used IBM Watson to build a virtual assistant that enhances teaching, learning and information access - Watson, last accessed 2018/08/17. https://www.ibm.com/blogs/watson/2017/08/bolton-college-uses-ibm-watson-ai-to-buildvirtual-assistant-that-enhances-teaching-learning-and-assessment/

30. What happened when a professor built a chatbot to be his teaching assistant - The Washington Post, last accessed 2018/08/13. https://www.washingtonpost.com/news/innovations/wp/2016/05/11/this-professorstunned-his-students-when-he-revealed-the-secret-identity-of-his-teachingassistant/?noredirect $=$ on\&utm term $=.87781 \mathrm{a} 0 \mathrm{e} 81 \mathrm{de}$

31. The ethics of Artificial Intelligence in education - University Business, last accessed 2018/08/10. https://universitybusiness.co.uk/Article/the-ethics-ofartificial-intelligence-ineducation-who-care/

32. Key Changes with the General Data Protection Regulation - EUGDPR, last accessed 2019/02/08. https://eugdpr.org/the-regulation/

33. Tsang, L., Mulryne, J., Strom, L.: The impact of artificial intelligence on medical innovation in the European Union and United States. Intellectual Property \& Technology Law Journal, 2018 (2017).

34. Wachter S, Mittelstadt B, Floridi L.: Why a right to explanation of automated decisionmaking does not exist in the general data protection regulation. International Data Privacy Law 7(2), 76-99 (2017).

35. Europeans Express Positive Views on AI and Robotics: Report on Preliminary Results from Public Consultations | McCarthy Tetrault, last accessed 2019/02/01. https://www.mccarthy.ca/en/insights/blogs/cyberlex/europeans-express-positive-views-aiand-robotics-report-preliminary-results-public-consultations 
36. Draft Ethics Guidelines for Trustworthy AI | Digital Single Market, last accessed 2019/01/30. https://ec.europa.eu/digital-single-market/en/news/draft-ethics-guidelinestrustworthy-ai

37. AI Principles - Future of Life Institute, last accessed 2019/02/05. https://futureoflife.org/ai-principles/?cn-reloaded=1

38. Ethically Aligned Design, Version 2 (EADv2) | IEEE Standards Association, last accessed 2018/12/29. https://ethicsinaction.iee.org/

39. Papanikolaou, K.A., Grigoriadou, M., Kornilakis, H., Magoulas, G.D.: Personalizing the Interaction in a Web-based Educational Hypermedia System: the case of INSPIRE. User modeling and user-adapted interaction 13(3), 213-267 (2003).

40. Brusilovsky, P., Peylo, C.: Adaptive and Intelligent Web-based Educational Systems. International Journal of Artificial Intelligence in Education 13, 156-169 (2003).

41. Sidney, K.D., Craig, S.D., Gholson, B., Franklin, S., Picard, R., Graesser, A.C.: Integrating affect sensors in an intelligent tutoring system. In Affective Interactions: The Computer in the Affective Loop Workshop, 7-13 (2005).

42. Arroyo, I., Cooper, D.G., Burleson, W., Woolf, B.P., Muldner, K., Christopherson, R.: Emotion sensors go to school. In AIED Vol. 200, 17-24, (2009)

43. Crockett, K., Latham, A., Whitton, N.: On predicting learning styles in conversational intelligent tutoring systems using fuzzy decision trees. International Journal of HumanComputer Studies 97, 98-115 (2017).

44. Latham, A., Crockett, K., McLean, D.: An adaptation algorithm for an intelligent natural language tutoring system. Computers \& Education, 71, 97-110 (2014).

45. The Flesch Reading Ease and Flesch-Kincaid Grade Level - readable.io, last accessed 2018/06/05. https://readable.io/blog/the-flesch-reading-ease-and-flesch-kincaid-gradelevel/ 